\title{
BMJ Open Randomised controlled trial of vitamin D supplementation in sarcoidosis
}

\author{
Mark J Bolland, ${ }^{1}$ Margaret L Wilsher, ${ }^{1,2}$ Andrew Grey, ${ }^{1}$ Anne M Horne, ${ }^{1}$ \\ Sheryl Fenwick, ${ }^{1}$ Greg D Gamble, ${ }^{1}$ lan R Reid ${ }^{1}$
}

To cite: Bolland MJ, Wilsher ML, Grey A, et al. Randomised controlled trial of vitamin $D$ supplementation in sarcoidosis. BMJ Open 2013:3:e003562. doi:10.1136/bmjopen-2013003562

- Prepublication history and additional material for this paper is available online. To view these files please visit the journal online (http://dx.doi.org/10.1136/ bmjopen-2013-003562)

Received 8 July 2013

Revised 22 August 2013

Accepted 7 October 2013

CrossMark

\begin{abstract}
${ }^{1}$ Department of Medicine, University of Auckland, Auckland, New Zealand ${ }^{2}$ Green Lane Respiratory Services, Auckland District Health Board, Auckland, New Zealand
\end{abstract}

Correspondence to Dr Mark Bolland; m.bolland@auckland.ac.nz

\section{ABSTRACT}

Objectives: The role vitamin $D$ intake/production plays in sarcoidosis-associated hypercalcaemia is uncertain. However, authoritative reviews have recommended avoiding sunlight exposure and vitamin D supplements, which might lead to adverse skeletal outcomes from vitamin $D$ insufficiency. We investigated the effects of vitamin $D$ supplementation on surrogate measures of skeletal health in patients with sarcoidosis and vitamin $\mathrm{D}$ insufficiency.

Design: Randomised, placebo-controlled trial.

Setting: Clinical research centre.

Participants: 27 normocalcaemic patients with sarcoidosis and 25-hydroxyvitamin D (250HD) $<50 \mathrm{nmol} / \mathrm{L}$.

Intervention: $50000 \mathrm{IU}$ weekly cholecalciferol for 4 weeks, then $50000 \mathrm{IU}$ monthly for 11 months or placebo.

Primary and secondary outcome measures: The primary endpoint was the change in serum calcium over 12 months, and secondary endpoints included measurements of calcitropic hormones, bone turnover markers and bone mineral density (BMD).

Results: The mean age of participants was 57 years and $70 \%$ were women. The mean (SD) screening $250 \mathrm{HD}$ was $35(12)$ and $38(9) \mathrm{nmol} / \mathrm{L}$ in the treatment and control groups, respectively. Vitamin $D$ supplementation increased $250 \mathrm{HD}$ to $94 \mathrm{nmol} / \mathrm{L}$ after 4 weeks, $84 \mathrm{nmol} / \mathrm{L}$ at 6 months and $78 \mathrm{nmol} / \mathrm{L}$ at 12 months, while levels remained stable in the control group. 1,25-Dihydroxy vitamin $D$ levels were significantly different between the groups at 4 weeks, but not at 6 or 12 months. There were no between-groups differences in albumin-adjusted serum calcium, $24 \mathrm{~h}$ urine calcium, markers of bone turnover, parathyroid hormone or BMD over the trial. One participant developed significant hypercalcaemia after 6 weeks (total cholecalciferol dose 250000 IU).

Conclusions: In patients with sarcoidosis and 250HD $<50 \mathrm{nmol} / \mathrm{L}$, vitamin $\mathrm{D}$ supplements did not alter average serum calcium or urine calcium, but had no benefit on surrogate markers of skeletal health and caused one case of significant hypercalcaemia.

Trial registration: This trial is registered at the Australian New Zealand Clinical Trials Registry (http://www.anzctr.org.au). The registration number is ACTRN12607000364471, date of registration 5/7/2007.

\section{ARTICLE SUMMARY}

Strength and limitations of the study

- The study had limited power to detect small differences in bone density and bone turnover markers.

- Few participants had 25-hydroxyvitamin D levels $<25 \mathrm{nmol} / \mathrm{L}$, and therefore the findings may not apply to individuals with very low vitamin D levels.

\section{INTRODUCTION}

Hypercalcaemia occurs commonly in sarcoidosis, with an estimated prevalence of $4-11 \% .^{12}$ Hypercalcaemia results from dysregulated production of 1,25-dihydroxyvitamin D $(1,25 \mathrm{OHD})$ by activated macrophages in granulomata. ${ }^{3}$ Although the mechanism of hypercalcaemia is known, the role of vitamin $\mathrm{D}$ intake and production is less certain. On the one hand, cases of hypercalcaemia and sarcoidosis precipitated by sunlight exposure or vitamin D supplements have been reported, ${ }^{4-8}$ and there is a seasonal variation in 1,250HD levels ${ }^{9}$ and the prevalence of hypercalcaemia. ${ }^{7910}$ These findings suggest that increases in 25-hydroxyvitamin D (25OHD) levels through sunlight exposure or vitamin D intake contribute to hypercalcaemia. On the other hand, studies have reported no correlation between 25OHD, 1,25OHD and serum calcium $;{ }^{11}$ historical studies of treatment with very large doses of vitamin D (target $100000 \mathrm{IU} /$ day for 5-212 days) produced hypercalcaemia in only $4 / 24$ patients, ${ }^{12}$ and patients with sarcoidosis and glucocorticoid-induced osteoporosis commonly take vitamin D supplements without developing hypercalcaemia. ${ }^{13}$ Furthermore, countries at higher latitudes do not have consistently lower prevalence of hypercalcaemia in sarcoidosis than countries closer to the equator, ${ }^{1}$ and prevalence of hypercalcaemia in sarcoidosis is similar in countries with and without dietary vitamin $\mathrm{D}$ fortification. ${ }^{6}$ These findings suggest that vitamin $\mathrm{D}$ intake and 
production are not the sole causes of hypercalcaemia in sarcoidosis.

Despite the conflicting evidence over the role of vitamin D intake/production in sarcoidosis-associated hypercalcaemia, several authoritative reviews have recommended avoidance of sunlight exposure and vitamin D supplements. ${ }^{6-8}$ Adopting such recommendations is likely to lead to vitamin D insufficiency, which is associated with various adverse skeletal outcomes including secondary hyperparathyroidism, increased bone turnover, low bone mineral density (BMD) and increased risk of fracture. ${ }^{14}$ There is a high prevalence of low BMD in cross-sectional studies of patients with sarcoidosis, ${ }^{713}{ }^{15-18}$ and glucocorticoid use is common and well known to have adverse skeletal effects. Thus, it is possible that treatment recommendations of sarcoidosis may worsen skeletal health by inadvertently promoting vitamin D insufficiency.

There has been recent interest in the effects of vitamin D supplements in patients with sarcoidosis. ${ }^{19-22}$ We have conducted a randomised controlled trial to determine the effects of vitamin D supplementation on surrogate measures of skeletal health in patients with sarcoidosis and vitamin D insufficiency.

\section{METHODS}

\section{Participants}

Patients with sarcoidosis attending the interstitial lung disease clinic at our hospital were invited to participate. Newspaper advertisements were also placed. Potential participants were eligible if they had sarcoidosis diagnosed by biopsy and/or typical pattern on high- resolution computed tomography and screening 25OHD $<50 \mathrm{nmol} / \mathrm{L}$, but were excluded if they had serum creatinine $>150 \mu \mathrm{mol} / \mathrm{L}$, nephrocalcinosis, albumin-adjusted serum calcium $>2.55 \mathrm{mmol} / \mathrm{L}$, concurrent major systemic illness or BMD T score $<-2.5$ at the spine or hip. Participants were recruited between September 2007 and December 2010. The flow of participants is shown in figure 1 .

\section{Protocol}

Participants were randomised to receive either $50000 \mathrm{IU}$ of cholecalciferol or placebo weekly for 4 weeks followed by $50000 \mathrm{IU}$ cholecalciferol or placebo every month for 11 months. Patients were asked to continue their usual diet to maintain their dietary calcium intake in accordance with locally recommended practice. Calcium supplements were not administered. Treatment allocations were randomised by the study statistician, using a variable block size schedule, based on computer-generated random numbers. Study medication was dispensed into identical bottles and labelled with participant numbers by a staff member not otherwise involved in the study. To ensure masking, only the statistician and this staff member had access to treatment allocation, and neither had contact with participants. All other study personnel and participants were blinded to treatment allocation throughout.

The primary endpoint was the change in serum calcium during 12 months with vitamin $\mathrm{D}$ supplementation. Secondary endpoints were the change in urine calcium, change in markers of bone turnover and change in BMD during 12 months. It was planned to

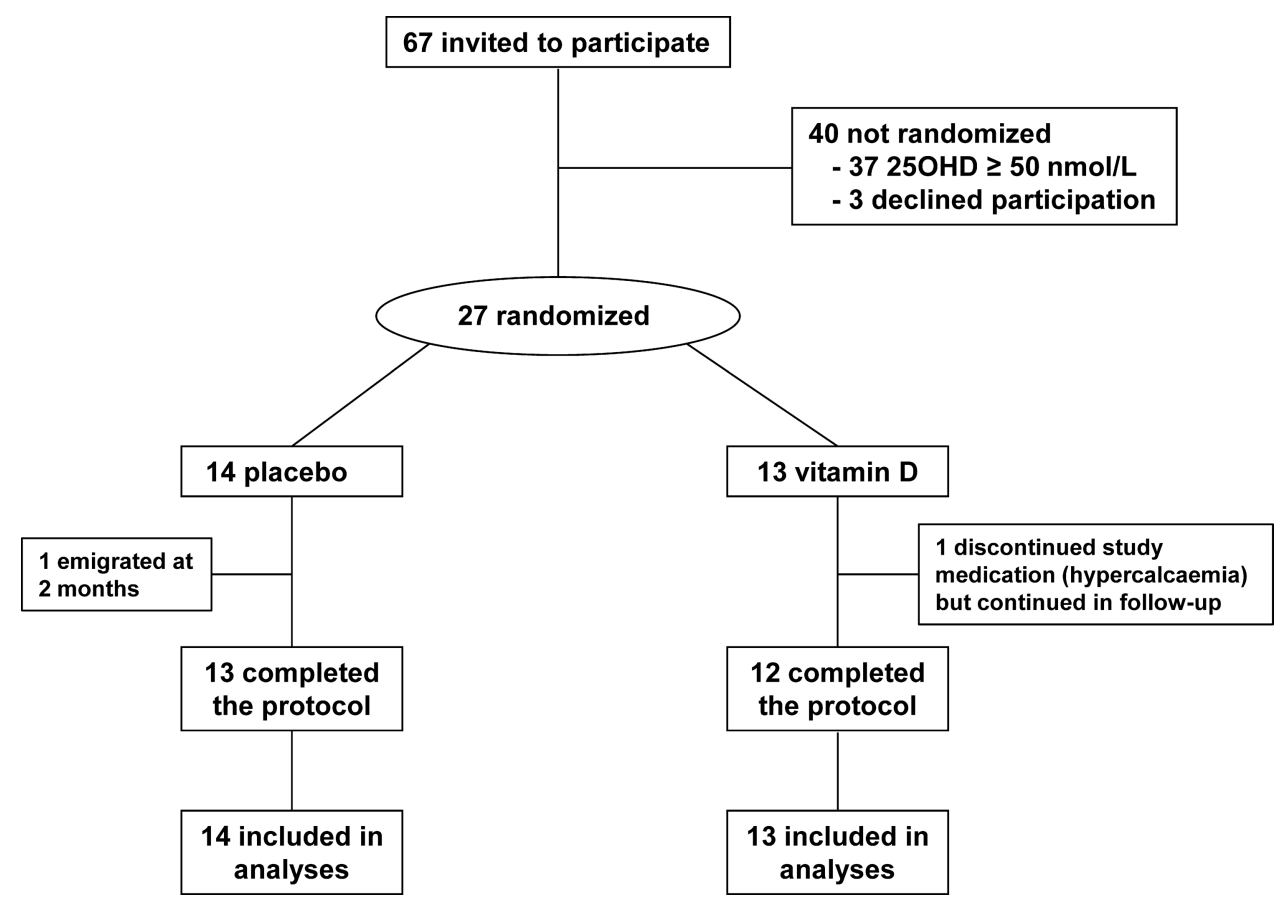

Figure 1 Flow of participants. 
recruit 40 participants, for which the study had $>80 \%$ power $(\alpha=0.05)$ to detect a difference in serum calcium of $0.10 \mathrm{mmol} / \mathrm{L}$ between groups. Recruitment was stopped after more than 3 years when 27 participants were recruited.

\section{Measurements}

At baseline, every 2 weeks for 8 weeks, then at 12, 16, 26, 39 and 52 weeks, fasting blood and second-voided morning urine samples were collected. Samples for calcitropic hormones and bone turnover markers were stored at $-70^{\circ} \mathrm{C}$ until they were batch-analysed. At baseline, 4, 26 and 52 weeks, $24 \mathrm{~h}$ urine samples were collected. The following assays were used: the screening 25OHD was measured by radioimmunoassay (RIA) (DiaSorin, Stillwater, Minnesota, USA), but all 25OHD samples from the study including the baseline sample were measured by liquid chromatography, tandem mass spectrometry (LC-MS/MS) (ABSciex API 4000); $1,25 \mathrm{OHD}$ by RIA (IDS, Tyne and Wear, UK), serum

Table 1 Baseline characteristics

\begin{tabular}{|c|c|c|}
\hline & $\begin{array}{l}\text { Vitamin D } \\
n=13\end{array}$ & $\begin{array}{l}\text { Placebo } \\
n=14\end{array}$ \\
\hline Age (years) & $56(10)$ & $57(9)$ \\
\hline Female & $10(77)$ & $9(64)$ \\
\hline \multicolumn{3}{|l|}{ Ethnicity } \\
\hline European & $10(77)$ & $9(64)$ \\
\hline Indian & $1(8)$ & $3(21)$ \\
\hline Other & $1(8)$ & $2(14)$ \\
\hline Weight (kg) & 75 (19) & $72(13)$ \\
\hline Dietary calcium intake (mg/day) & $730(670)$ & $660(330)$ \\
\hline \multicolumn{3}{|l|}{ Smoking status } \\
\hline Current & $3(23)$ & $0(0)$ \\
\hline Never smoked & $8(63)$ & $9(64)$ \\
\hline \multicolumn{3}{|l|}{ Glucocorticoid use } \\
\hline Past oral use & $7(54)$ & $9(64)$ \\
\hline Current oral use & $1(8)$ & $0(0)$ \\
\hline Current inhaled use & $6(46)$ & $1(7)$ \\
\hline \multicolumn{3}{|l|}{ Sarcoidosis extent } \\
\hline Pulmonary involvement & $11(85)$ & $8(57)$ \\
\hline Extrapulmonary involvement & $6(46)$ & $7(50)$ \\
\hline \multicolumn{3}{|l|}{ Chest radiograph stage at baseline } \\
\hline 0 & $1(10)$ & $6(46)$ \\
\hline 1 & $1(10)$ & $1(8)$ \\
\hline 2 & $1(10)$ & $0(0)$ \\
\hline 3 & $3(30)$ & $4(31)$ \\
\hline 4 & $4(40)$ & $2(15)$ \\
\hline \multicolumn{3}{|l|}{ Bone density $\left(\mathrm{g} / \mathrm{cm}^{2}\right)$} \\
\hline Lumbar spine & $1.16(0.19)$ & $1.13(0.11)$ \\
\hline T score & $-0.2(1.6)$ & $-0.6(0.9)$ \\
\hline Total hip & $0.95(0.11)$ & $0.93(0.11)$ \\
\hline T score & $-0.6(0.9)$ & $-0.8(0.9)$ \\
\hline Femoral neck & $0.89(0.13)$ & $0.91(0.09)$ \\
\hline T score & $-1.2(1.0)$ & $-0.9(0.7)$ \\
\hline Total body & $1.15(0.10)$ & $1.11(0.07)$ \\
\hline Adjusted serum calcium (mmol/L) & $2.24(0.06)$ & $2.26(0.12)$ \\
\hline Serum phosphate (mmol/L) & $1.23(0.15)$ & $1.06(0.17)$ \\
\hline Serum creatinine (mmol/L) & $74(14)$ & $77(12)$ \\
\hline $24 \mathrm{~h}$ urine calcium (mmol/day) & $4.6(3.4)$ & $6.6(5.2)$ \\
\hline Screening 25-hydroxyvitamin D (nmol/L)* & $35(12)$ & $38(9)$ \\
\hline Baseline 25-hydroxyvitamin D (nmol/L)* & $40(17)$ & $45(17)$ \\
\hline 1,25-dihydroxyvitamin D (pmol/L) & $109(34)$ & $116(25)$ \\
\hline Parathyroid hormone (pmol/L) & $4.0(1.6)$ & $4.9(2.0)$ \\
\hline P1NP (ug/L) & $37(12)$ & $40(15)$ \\
\hline$\beta-\mathrm{CTX}(\mathrm{ng} / \mathrm{L})$ & $310(130)$ & $360(210)$ \\
\hline
\end{tabular}


parathyroid hormone (PTH) by electrochemiluminescence immunoassay (E170, Roche Diagnostics, Indianapolis, Indiana, USA); serum procollagen type-I N-terminal propeptide (P1NP) and serum $\beta$-C-terminal telopeptide of type I collagen (CTx) by the Roche Elecsys 2010 platform (Roche Diagnostics). BMD was measured every 6 months at the lumbar spine, proximal femur and total body using a GE Prodigy dual-energy X-ray absorptiometer (GE Lunar, Madison, Wisconsin, USA). Daily calcium intake was assessed at baseline using a validated questionnaire. $^{23}$

\section{Statistics}

Baseline differences between groups for continuous variables were assessed using Student's t test, and for categorical variables using the $\chi^{2}$ test. All analyses were carried out on an intention-to-treat basis. A mixed models approach to repeated measures with an unstructured covariance structure was used to examine the time course of response in the treatment and control arms for serum calcium, urine calcium, calcitropic hormones, bone turnover markers and BMD measurements by fitting main and treatment-by-time interaction effects. Post hoc comparisons between groups at individual time points were explored using the method of Tukey. BMD data were analysed using raw data, although results are presented as percentage change from baseline adjusted for baseline between-groups differences, for ease of interpretation. All tests were two-tailed and hypothesis tests were deemed significant for $\mathrm{p}<0.05$. All statistical analyses were carried out using the SAS software package (SAS Institute, Cary, North Carolina, USA, V.9.2)

\section{RESULTS}

The baseline characteristics of the two groups were similar (table 1). The mean (range) $25 \mathrm{OHD}$ at the study screening visit was $35(14-48) \mathrm{nmol} / \mathrm{L}$ in the treatment group, and $38(12-49) \mathrm{nmol} / \mathrm{L}$ in the controls. The baseline 25OHD measurements from the first study visit (average 3 weeks after screening 25OHD) that were stored and then measured at the end of the study using a different assay were slightly higher than the screening $25 \mathrm{OHD}$ in both groups (table 1). Vitamin D supplementation led to an immediate increase in 25OHD levels, and a sustained difference between the groups that persisted throughout the trial $(\mathrm{p}<0.001$; figure 2$)$. There was also an immediate increase in 1,25OHD levels in response to vitamin $\mathrm{D}$ supplementation, but this did not persist. While the between-groups differences over the trial were statistically significant $(\mathrm{p}=0.007)$, by the end of the trial $1,25 \mathrm{OHD}$ levels were similar in both groups (figure 2).

Figure 3 shows that vitamin D supplements had no effect on either average albumin-adjusted serum calcium $(\mathrm{p}=0.46)$ or $24 \mathrm{~h}$ urine calcium levels $(\mathrm{p}=0.10)$ throughout the trial. There were no between-group differences at any time point in participants with $24 \mathrm{~h}$ urine calcium $>10 \mathrm{mmol} /$ day (baseline vitamin $\mathrm{D}$ vs control 1 vs $4 ; 4$ weeks 4 vs $4 ; 16$ weeks 1 vs $2 ; 52$ weeks 3 vs 2 ). One participant in the vitamin $\mathrm{D}$ group and none in the control group had sustained hypercalcuria with $24 \mathrm{~h}$ urine calcium $>10 \mathrm{mmol} /$ day in all the three visits during follow-up. One participant developed hypercalcaemia during the trial-a 51-year-old woman diagnosed with sarcoidosis 2 years prior to study entry, with bilateral hilar lymphadenopathy, liver and lung involvement. She was taking inhaled glucocorticoids at study entry but no other medication. She was assigned to vitamin D
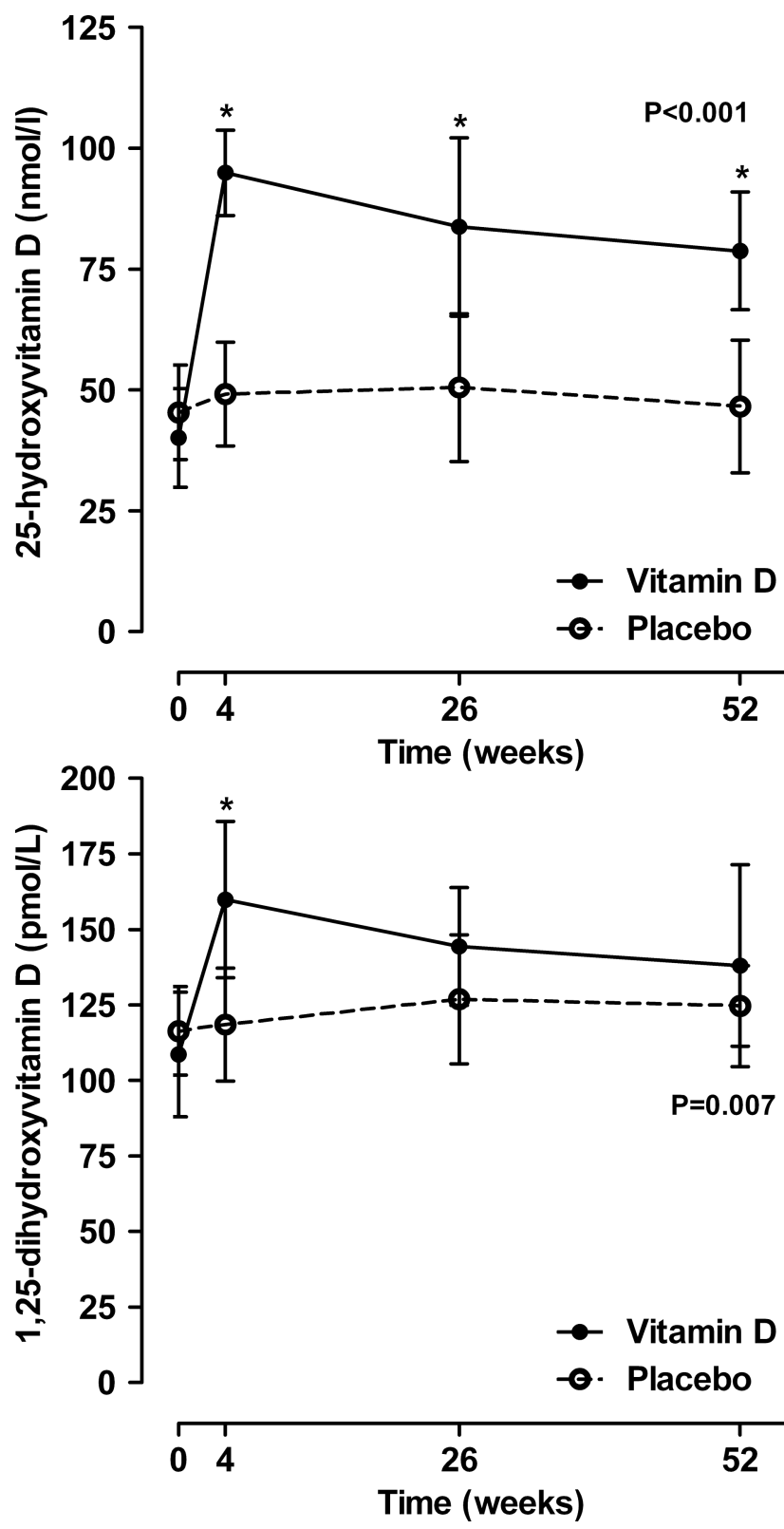

Figure 2 The effect of vitamin D supplementation on 25-hydroxyvitamin D and 1,25-dihydroxyvitamin D levels. Data are mean and $95 \% \mathrm{Cl}$. p Values are for time-by-treatment interaction. Asterisks indicate significant between-groups differences at individual points. 

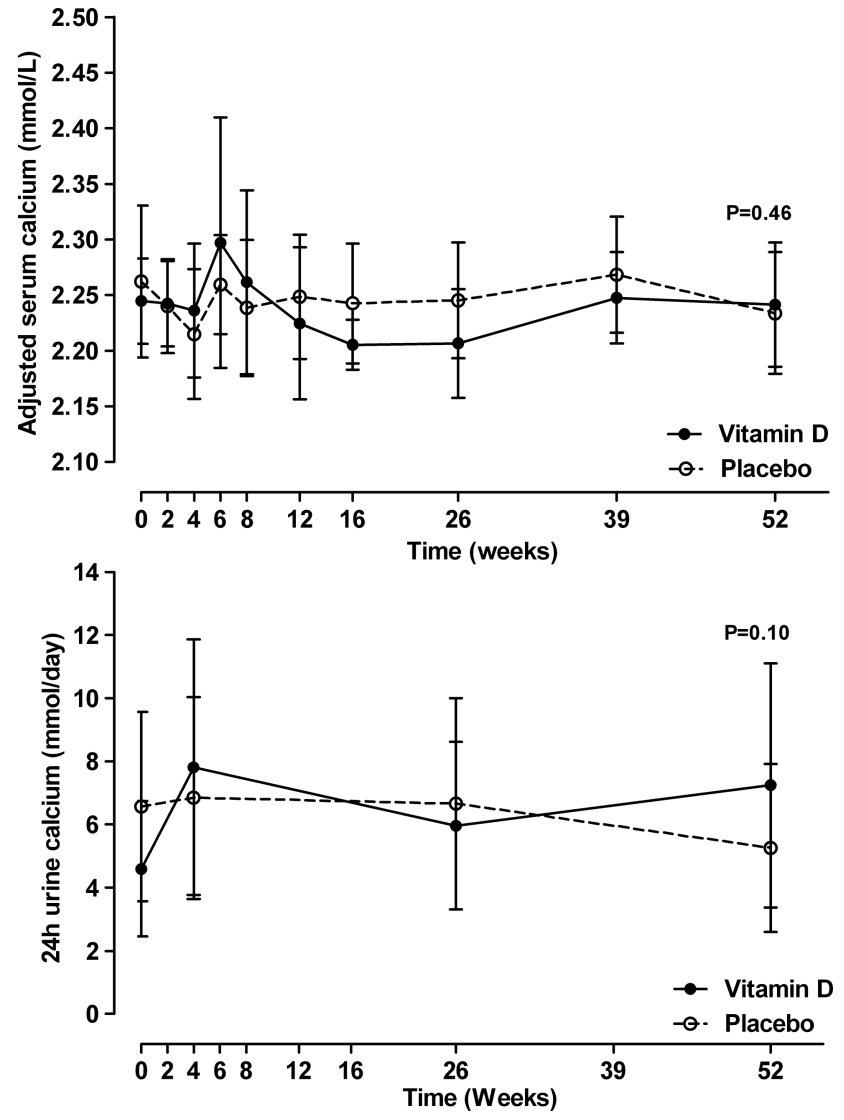

Figure 3 The effect of vitamin D supplementation on albumin-adjusted serum calcium and $24 \mathrm{~h}$ urine calcium levels. Data are mean and $95 \% \mathrm{Cl}$. p Values are for time-by-treatment interaction.

treatment and table 2 shows that hypercalcaemia was recognised at 6 weeks, by which time she had taken five $50000 \mathrm{IU}$ doses of cholecalciferol. She was vitamin D deficient at baseline, and treatment increased her 25OHD level to $69 \mathrm{nmol} / \mathrm{L}$. There was a marked increase in $1,25 \mathrm{OHD}, 24 \mathrm{~h}$ urine calcium, serum phosphate and creatinine levels and suppression of the PTH levels following vitamin D supplementation, but she remained asymptomatic throughout. No further study medication was taken and the biochemical abnormalities resolved without specific treatment by week 16 of the trial. When this participant was excluded from the analyses for serum calcium and $24 \mathrm{~h}$ urine calcium, the results did not change substantially except that there was no visible rise in the average albumin-adjusted serum calcium at 6 and 8 weeks in the vitamin D group (data not shown).

The effect of vitamin D supplements on bone turnover markers and PTH are shown in figure 4 and on BMD in figure 5. Vitamin D supplementation had no effect on any of these variables ( $p>0.16$ for all variables).

Other than the one participant treated with vitamin D who developed hypercalcaemia (proportion $8 \%, 95 \%$ CI $1 \%$ to $33 \%$ ), there were no other adverse events potentially related to treatment during the trial. One participant (randomised to vitamin D) required prolonged treatment with oral glucocorticoids, and one participant (randomised to placebo) received a single infusion of zoledronic acid at 11 months because of an underlying neurological disorder that had led to an increased risk of falls and fracture.

\section{DISCUSSION}

Vitamin D supplementation of patients with sarcoidosis and vitamin $\mathrm{D}$ insufficiency did not alter average serum calcium or urine calcium levels, and also did not affect BMD or markers of bone turnover but caused one case of significant hypercalcaemia. 25OHD levels were in a range many experts consider suboptimal at baseline (average $<50 \mathrm{nmol} / \mathrm{L}$ ) and vitamin $\mathrm{D}$ supplementation led to average 25OHD levels of $>75 \mathrm{nmol} / \mathrm{L}$ throughout the trial, levels generally considered to indicate adequate

\begin{tabular}{|c|c|c|c|c|c|c|c|c|}
\hline Weeks* & $\begin{array}{l}\text { Dietary } \\
\text { calcium } \\
\text { (mg/day) }\end{array}$ & $\begin{array}{l}\text { Serum } \\
\text { calcium† } \\
\text { (mmol/L) }\end{array}$ & $\begin{array}{l}\text { Serum } \\
\text { phosphate } \\
\text { (mmol/L) }\end{array}$ & $\begin{array}{l}\text { Serum } \\
\text { creatinine } \\
\text { ( } \mu \mathrm{mol} / \mathrm{L} \text { ) }\end{array}$ & $\begin{array}{l}24 \text { h Urine } \\
\text { calcium } \\
\text { (mmol/day) }\end{array}$ & $\begin{array}{l}\text { 25OHD } \\
\text { (nmol/L) }\end{array}$ & $\begin{array}{l}\text { 1,25OHD } \\
\text { (pmol/L) }\end{array}$ & $\begin{array}{l}\text { PTH } \\
\text { (pmol/L) }\end{array}$ \\
\hline 0 & 460 & 2.26 & 1.24 & 76 & 4.2 & 18 & 77 & 2.3 \\
\hline 2 & & 2.36 & 1.28 & 74 & & & & \\
\hline 4 & & 2.48 & 1.57 & 83 & 14.4 & 69 & 218 & 0.9 \\
\hline 6 & & 2.88 & 1.55 & 112 & & & & \\
\hline 7 & & 2.87 & 1.31 & 125 & & & & \\
\hline 8 & & 2.65 & 1.45 & 124 & & & & \\
\hline 12 & & 2.46 & 1.23 & 93 & & & & \\
\hline 16 & & 2.22 & 1.14 & 75 & & & & \\
\hline 26 & & 2.28 & 1.04 & 71 & & 31 & 81 & 2.2 \\
\hline 52 & & 2.27 & 1.11 & 78 & 6.7 & 41 & 77 & 2.1 \\
\hline
\end{tabular}



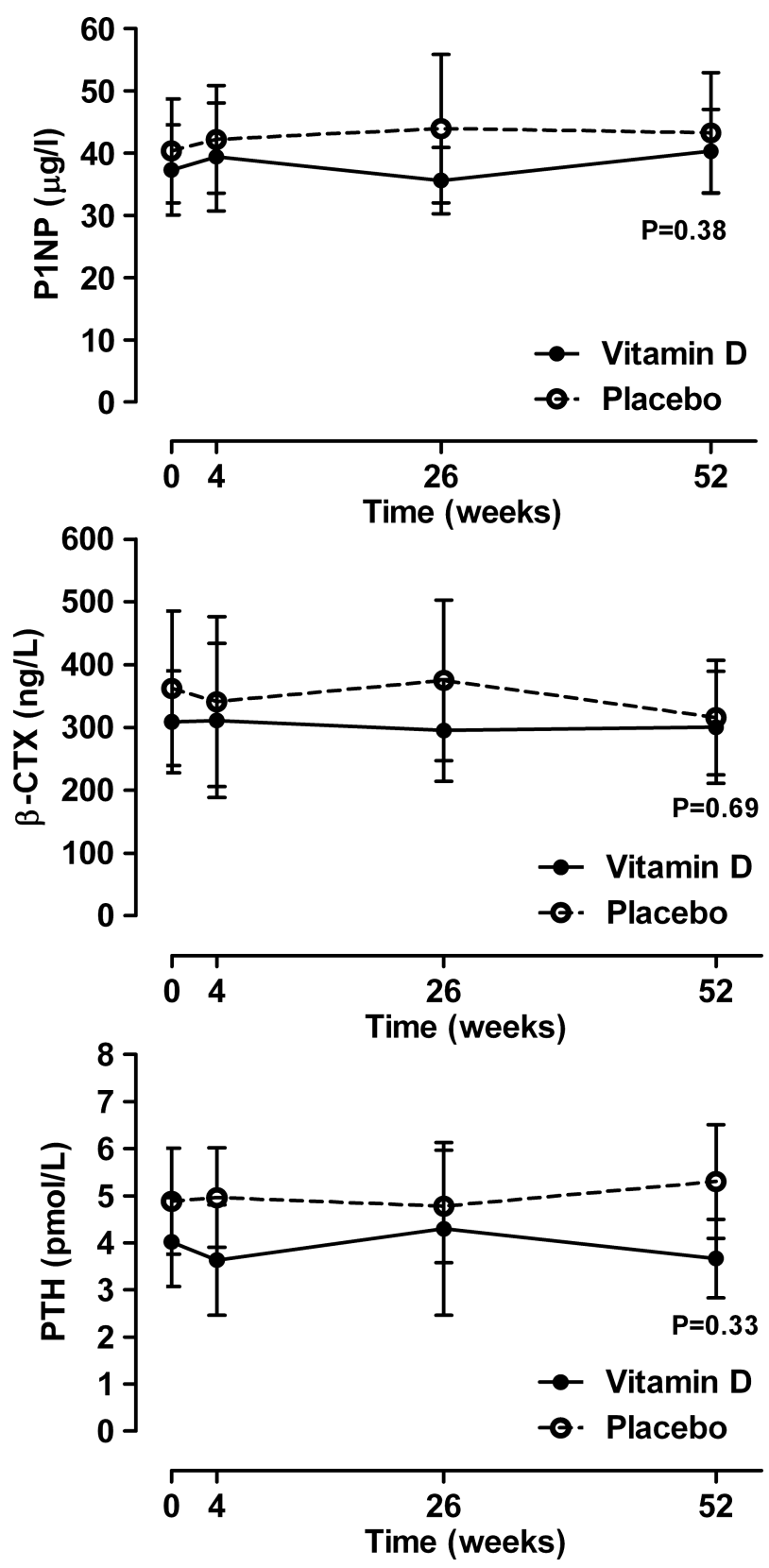

Figure 4 The effect of vitamin D supplementation on bone turnover markers and serum parathyroid hormone. Data are mean and $95 \% \mathrm{Cl}$. p Values are for time-by-treatment interaction. P1NP, Procollagen type-I N-terminal propeptide; $\beta$-CTx, $\beta$-C-terminal telopeptide of type I collagen.

vitamin D status. Thus, our findings of an absence of benefit from vitamin D supplements, together with infrequent but significant hypercalcaemia, suggest that there is little indication for vitamin D supplements in patients with sarcoidosis and vitamin D insufficiency.

Recent research has linked low 25OHD levels with numerous adverse non-skeletal outcomes. ${ }^{24}$ This information, when added to the existing data linking low $25 \mathrm{OHD}$ levels with adverse skeletal outcomes, ${ }^{14}$ has led to renewed interest in the role of vitamin $\mathrm{D}$ in health. In clinical practice, there has been a large increase in measurement of $25 \mathrm{OHD}^{2526}$ and calls for widespread

vitamin D supplementation. ${ }^{27}$ However, these associations between low vitamin $\mathrm{D}$ status and adverse health outcomes have been generated from observational studies which cannot determine causality. There are now a growing number of randomised controlled trials that have not shown benefits from vitamin $\mathrm{D}$ supplements on a wide range of endpoints. Thus, meta-analyses of such trials have shown no benefit of vitamin D supplementation (when used without coadministered calcium supplements) on falls, ${ }^{28}$ fractures,${ }^{29}$ mortality, ${ }^{30}$ cardiovascular events $^{30}$ and cancer. ${ }^{31}$ In our study, which was powered to assess serum calcium rather than BMD effects, we did not find evidence for benefit of vitamin $\mathrm{D}$ supplements on surrogate markers of skeletal health in a group of patients with sarcoidosis who had mildly low 25OHD levels, consistent with these findings.

The mechanism of hypercalcaemia in sarcoidosis is well described. Extrarenal production of 1,25OHD in activated macrophages in granulomata leads to increased intestinal calcium absorption and increased bone resorption which collectively produce hypercalcaemia. ${ }^{3}$ It is unclear whether circulating $25 \mathrm{OHD}$ levels are implicated in causing hypercalcaemia, with some evidence supporting ${ }^{4-10}$ and some not supporting ${ }^{1}{ }^{6}$ 11-13 each viewpoint, as discussed earlier. Our study tends to support the former view for two reasons: first, one patient developed significant hypercalcaemia within a short time of starting vitamin D supplements, and there was prompt resolution of the hypercalcaemia without other treatment after the supplements were stopped. Second, in the entire cohort there was a rapid increase in 1,25OHD with vitamin $\mathrm{D}$ supplements, although the increase did not persist. Both pieces of data suggest that abrupt changes in 25OHD can increase 1,25OHD, and in a minority of patients this can cause hypercalcaemia. The characteristics that predispose to the development of hypercalcaemia remain unclear. It is possible that increasing 25OHD more slowly using small, incrementally increasing doses of vitamin $\mathrm{D}$, may avoid this complication, but this would need to be tested in closely monitored clinical trials.

Our study has several limitations. It is a small study and therefore may be at risk of type II error. We carried out simulations to explore what effect sizes could have been statistically significant in this study. We simulated an increased effect size in the treatment group (without varying data in the placebo group or the sample size) in the models used in the study analyses. A difference between the groups at 1 year of $0.06 \mathrm{mmol} / \mathrm{L}$ in serum calcium, the primary endpoint, would have reached conventional statistical significance. This is $60 \%$ of the value used in the study power calculation $(0.1 \mathrm{mmol} / \mathrm{L})$ that we considered to be clinically relevant when designing the study. Similarly, the corresponding between-groups differences that would have reached statistical significance for the other main endpoints were: $2.4 \mathrm{pmol} / \mathrm{L}$ for PTH, $7 \mu \mathrm{g} / \mathrm{L}$ for P1NP, $140 \mathrm{ng} / \mathrm{L}$ for CTX and $0.5 \%-1.9 \%$ for BMD, depending on site. Differences 
Figure 5 The effect of vitamin D supplementation on bone mineral density (BMD). Data are mean and $95 \% \mathrm{Cl}$ for the percentage change from baseline adjusted for baseline BMD. $p$ Values are for time-by-treatment interaction.
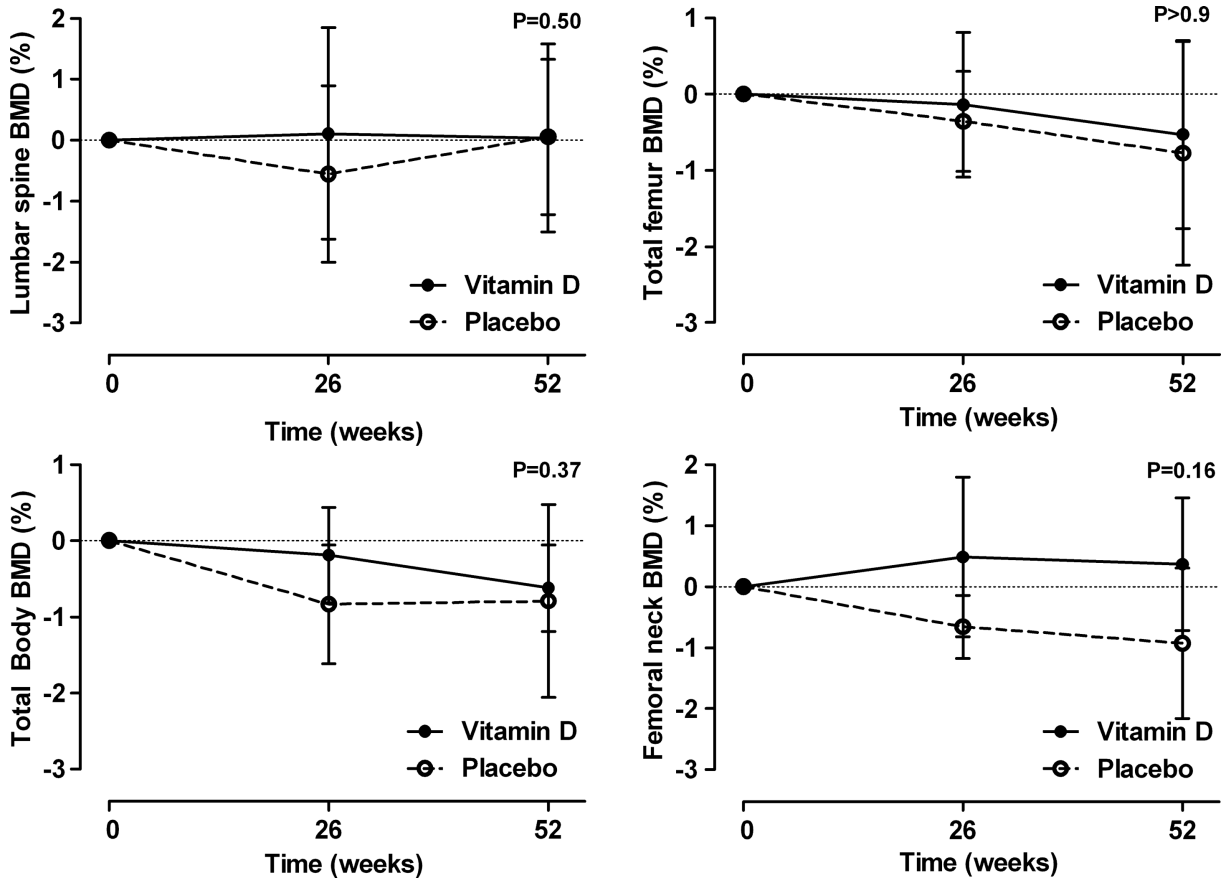

below these amounts would be of questionable clinical relevance. Thus, while small, the study did have more than adequate power to detect clinically relevant differences. A second limitation is regarding the screening vitamin D measurement. All participants had 25OHD $<50 \mathrm{nmol} / \mathrm{L}$ at the screening visit measured using a Diasorin RIA. All study samples for 25OHD were frozen and then assayed in a single batch at another laboratory using an LC-MS/MS assay. The 25OHD levels measured using LC-MS/MS were on average slightly higher than those measured using the Diasorin immunoassay, and $9 / 27$ participants had $25 \mathrm{OHD}>50 \mathrm{nmol} / \mathrm{L}$ at the baseline visit. Variation between results from different 25OHD assays is well described, and while LC-MS/MS is usually considered the gold standard, immunoassays and LC-MS/MS have limitations. ${ }^{32}$ Few participants had $25 \mathrm{OHD}<25 \mathrm{nmol} / \mathrm{L}$ at baseline, thus our results may not apply to individuals with very low $25 \mathrm{OHD}$ levels.

In summary, we did not find evidence of benefits on surrogate markers of skeletal health from vitamin D supplementation in patients with sarcoidosis and vitamin D insufficiency. However, there was evidence of harm with one case of significant hypercalcaemia. The absence of benefit together with the risk of infrequent but significant adverse effects suggests that there is little indication for vitamin D supplements in patients with sarcoidosis and vitamin D levels in the range in this study (12$49 \mathrm{nmol} / \mathrm{L})$.

Contributors MB, AG, AH, IR and MW designed the study. SF and AH ran the study. MB and $G G$ conducted the statistical analyses. MB drafted the article. All the authors critically reviewed the draft manuscript and approved the final version. MB is the guarantor.

Funding This study was funded by the Health Research Council of New Zealand, and the Greenlane Research and Education Fund.
Competing interests None.

Ethics approval The study received ethical approval from the Northern $\mathrm{X}$ regional ethics committee and the trial was registered with the Australian New Zealand Clinical Trials Registry, ACTRN12607000364471.

Provenance and peer review Not commissioned; externally peer reviewed.

Data sharing statement No additional data are available.

Open Access This is an Open Access article distributed in accordance with the Creative Commons Attribution Non Commercial (CC BY-NC 3.0) license, which permits others to distribute, remix, adapt, build upon this work noncommercially, and license their derivative works on different terms, provided the original work is properly cited and the use is non-commercial. See: http:// creativecommons.org/licenses/by-nc/3.0/

\section{REFERENCES}

1. James DG, Neville E, Siltzbach LE. A worldwide review of sarcoidosis. Ann N Y Acad Sci 1976;278:321-34.

2. Baughman RP, Teirstein AS, Judson MA, et al. Clinical characteristics of patients in a case control study of sarcoidosis. Am J Respir Crit Care Med 2001;164:1885-9.

3. Singer FR, Adams JS. Abnormal calcium homeostasis in sarcoidosis. N Engl J Med 1986;315:755-7.

4. Bell NH, Gill JR Jr, Bartter FC. On the abnormal calcium absorption in sarcoidosis. Evidence for increased sensitivity to vitamin D. Am J Med 1964;36:500-13

5. Sandler LM, Winearls CG, Fraher LJ, et al. Studies of the hypercalcaemia of sarcoidosis: effect of steroids and exogenous vitamin D3 on the circulating concentrations of 1,25-dihydroxy vitamin D3. Q J Med 1984;53:165-80.

6. Sharma OP. Vitamin D, calcium and sarcoidosis. Chest 1996;109:535-9.

7. Rizzato G. Clinical impact of bone and calcium metabolism changes

8. Conron M, Young C, Beynon HL. Calcium metabolism in sarcoidosis and its clinical implications. Rheumatology (Oxford) 2000;39:707-13.

9. Bonnema SJ, Moller J, Marving J, et al. Sarcoidosis causes abnormal seasonal variation in 1,25-dihydroxy-cholecalciferol. J Intern Med 1996;239:393-8.

10. Taylor RL, Lynch HJ Jr, Wysor WG Jr. Seasonal influence of sunlight on the hypercalcemia of sarcoidosis. Am J Med 1963;34:221-7. in sarcoidosis. Thorax 1998;53:425-9. 
11. Alberts $\mathrm{C}$, van den Berg $\mathrm{H}$. Calcium metabolism in sarcoidosis. A follow-up study with respect to parathyroid hormone and vitamin $D$ metabolites. Eur J Respir Dis 1986;68:186-94.

12. Larsson LG, Liljestrand $A$, Wahlund $H$. Treatment of sarcoidosis with calciferol. Acta Med Scand 1952;143:281-7.

13. Adler RA, Funkhouser HL, Petkov VI, et al. Glucocorticoid-induced osteoporosis in patients with sarcoidosis. Am J Med Sci 2003;325:1-6.

14. Lips P. Vitamin D deficiency and secondary hyperparathyroidism in the elderly: consequences for bone loss and fractures and therapeutic implications. Endocr Rev 2001;22:477-501.

15. Montemurro L, Fraioli P, Rizzato G. Bone loss in untreated longstanding sarcoidosis. Sarcoidosis 1991;8:29-34.

16. Rottoli $\mathrm{P}$, Gonnelli $\mathrm{S}$, Silitro $\mathrm{S}$, et al. Alterations in calcium metabolism and bone mineral density in relation to the activity of sarcoidosis. Sarcoidosis 1993;10:161-2.

17. Hamada K, Nagai S, Tsutsumi T, et al. Bone mineral density and vitamin $\mathrm{D}$ in patients with sarcoidosis. Sarcoidosis Vasc Diffuse Lung Dis 1999;16:219-23.

18. Sipahi S, Tuzun S, Ozaras R, et al. Bone mineral density in women with sarcoidosis. J Bone Miner Metab 2004;22:48-52.

19. Burke RR, Rybicki BA, Rao DS. Calcium and vitamin D in sarcoidosis: how to assess and manage. Semin Respir Crit Care Med 2010;31:474-84.

20. Sharma OP. Vitamin D and sarcoidosis. Curr Opin Pulm Med 2010;16:487-8

21. Sage RJ, Rao DS, Burke RR, et al. Preventing vitamin D toxicity in patients with sarcoidosis. J Am Acad Dermatol 2011;64:795-6.

22. Sweiss NJ, Lower EE, Korsten $\mathrm{P}$, et al. Bone health issues in sarcoidosis. Curr Rheumatol Rep 2011;13:265-72.
23. Angus RM, Sambrook PN, Pocock NA, et al. A simple method for assessing calcium intake in Caucasian women. J Am Diet Assoc 1989;89:209-14.

24. Holick MF. Vitamin D deficiency. N Engl J Med 2007;357: 266-81.

25. Sattar N, Welsh $\mathrm{P}$, Panarelli $\mathrm{M}$, et al. Increasing requests for vitamin D measurement: costly, confusing, and without credibility. Lancet 2012;379:95-6.

26. Bolland MJ, Grey A, Davidson JS, et al. Should measurement of vitamin $D$ and treatment of vitamin $D$ insufficiency be routine in New Zealand?. N Z Med J 2012;125:83-91.

27. Pearce SH, Cheetham TD. Diagnosis and management of vitamin D deficiency. BMJ 2010;340:b5664.

28. Murad MH, Elamin KB, Abu Elnour NO, et al. Clinical review: the effect of vitamin $D$ on falls: a systematic review and meta-analysis. $J$ Clin Endocrinol Metab 2011;96:2997-3006.

29. Avenell A, Gillespie WJ, Gillespie LD, et al. Vitamin D and vitamin D analogues for preventing fractures associated with involutional and post-menopausal osteoporosis. Cochrane Database Syst Rev 2009;2:CD000227.

30. Elamin MB, Abu Elnour NO, Elamin KB, et al. Vitamin D and cardiovascular outcomes: a systematic review and meta-analysis. $J$ Clin Endocrinol Metab 2011:96:1931-42.

31. Chung M, Lee J, Terasawa T, et al. Vitamin D with or without calcium supplementation for prevention of cancer and fractures: an updated meta-analysis for the U.S. preventive services task force. Ann Intern Med 2011;155:827-38.

32. Carter GD. 25-Hydroxyvitamin D assays: the quest for accuracy. Clin Chem 2009;55:1300-2. 